\title{
Strumal Carcinoid
}

National Cancer Institute

\section{Source}

National Cancer Institute. Strumal Carcinoid. NCI Thesaurus. Code C4292.

An ovarian neoplasm characterized by the presence of aberrant thyroid tissue and a carcinoid tumor. A minority of patients develop symptoms of functioning thyroid tissue.

The neuroendocrine carcinoid cells infiltrate the aberrant thyroid tissue and progressively replace the follicular lining cells. 